\title{
Ecologically safe composite building materials based on cellulose-containing solid household waste
}

\author{
Mikhail Bruyako ${ }^{1, *}$ and Larisa Grigoryeva ${ }^{1}$ \\ ${ }^{1}$ Moscow State University of Civil Engineering, Yaroslavskoe shosse, 26, Moscow, 129337, Russia
}

\begin{abstract}
In the article, three technological methods for obtaining a highfilled construction composite on the basis of gypsum binders and cellulosecontaining solid household waste are considered. The results of a study on the effect of changing the ratio of cardboard/gypsum binder, the specific pressing pressure, the sequence of combining the components on the properties of the final product are presented and presented. The strength of the material was determined from the final values of the flexural and compressive strengths until the specimen completely destroyed and at its $10 \%$ deformation. Studies have been carried out on the possibility of giving the building composite water resistance. The results of the research showed that the most optimal way of combining is the 2 way. The increase in water resistance of the resulting composites is significantly increased when using silicone hydrophobisers.
\end{abstract}

\section{Introduction}

In the conditions of modern economic activity of man, the ecological situation on our planet is deteriorating. Waste, by-products of production and life pollute the biosphere, cause deformation of ecological systems, disrupt the global cycle of substances and pose a threat to all mankind. The collection and processing of solid domestic waste (MSW) is not only a solution to the problem of environmental pollution and the search for cheap sources of raw materials, but also a separate type of economic activity [1]. At present, the Federal Classification Catalog of Waste operates in the Russian Federation [2].

According to the Ministry of Natural Resources of the Russian Federation, 70 million tons of solid household waste are generated annually in Russia. Of these, only 7 million tons are returned to economic circulation [3]. At the same time, the capacity of landfills for burial of such wastes at the limit, free areas for them remained just over 1.7 billion tons. Economic damage from the impact of production and consumption wastes amounts to $10 \%$ of the gross domestic product.

In accordance with regulations and sanitary norms, all types of waste, including solid waste, are subject to safe disposal methods for the public. In large megacities with a population of more than 1 million people, the annual volume of solid household waste per one inhabitant is up to 1 ton.

*Corresponding author: pehel@yandex.ru 
Solving the problems of environmental hazards of solid domestic and industrial wastes is relevant for all countries of the world community [4-6].

Thus, the study presents problems in the field of utilization of solid domestic and industrial wastes in the Republic of Kazakhstan [7]. The study analyzes the impact of urbanization, the level of education on the waste management system. With an increase in the educational level by $1 \%$, the amount of waste per capita is reduced by $3 \mathrm{~kg}$ [8].

The wider use of MSW as material resources for the production of secondary raw materials and its involvement in the production of the products of the national economy is the most rational solution to the problem of recycling. The production of various building materials is one of the most material-intensive industries.

In the development, production and operation of new building materials, their environmental safety must be taken into account [9]. When addressing this issue, it is necessary to pay attention to the environmental friendliness of all raw materials that make up the building materials, including those based on secondary resources.

The advantages of using recycled materials, including those obtained on the basis of solid household waste, include: saving on natural raw materials, releasing large areas of land on which they were to be built, freeing land from solid domestic waste and, most importantly, reducing the degree of pollution of the surrounding Environment.

$40 \%$ of the total volume of solid domestic waste are cellulose-containing materials cellulose-containing solid household waste (CSHW). CSHW are mainly represented mainly by cardboard and paper waste [10]. Using CSHW for obtaining secondary raw materials as a filler in the production of highly filled cellulose-containing building materials is an effective direction for their utilization.

In the building materials industry, cellulose-containing materials are used in the production of rolled waterproofing materials, wood fiber boards, gypsum fiber boards, ecowools. In this case, each material has its rather limited functional purpose (heat-insulating, waterproofing, finishing).

To ensure environmental friendliness as a binder for highly-filled CSHW, the most rational choice is the gypsum binder. The gypsum binder refers to mineral substances, it is non-combustible and corresponds to the set goal - obtaining environmentally safe material.

The main disadvantage of cellulose-containing filler is high flammability. Studies have shown that a reduction in the combustibility of cardboard is possible due to the introduction of various types of flame retardants, namely, inorganic phosphorus-containing compounds, as well as organic phosphorus, -sulfo-containing compounds. The most effective flame retardants are phosphates [11].

Given the specific properties of the filler and the possibility of its processing with various modifying additives, the developed material can be given such properties as reduced combustibility, increased biostability. This will significantly expand the scope of its functional use, as a structural material.

The analysis of existing production of building materials on the basis of cellulosecontaining fillers made it possible to conclude that the method and the sequence of combining the components of the raw mixture with the properties of the materials have a significant effect.

In this connection, attention was paid to the choice of the method for obtaining the molding mixture, the molding regimes, the quantitative and qualitative characteristics of the initial components on the properties of the final product.

To ensure the effectiveness of the use of materials based on cellulose-containing solid household waste, attention has been paid to issues of water resistance and reduction of the fire hazard of the final product.

The purpose of the study is to determine the optimal way to combine the components of the raw mix, determine its effect on the properties of the final product. 


\section{Materials and methods}

The to carry out experimental work in accordance with the tasks in the paper, we used: gypsum binder, crushed cardboard, hydrophobic additives, mixing water.

As a binder, the construction gypsum of G-7 was chosen (Table) [12].

Table 1. Variants of erecting floors by time periods (fragment).

\begin{tabular}{|c|c|c|c|c|}
\hline \multicolumn{2}{|c|}{ Setting time } & \multicolumn{2}{c|}{ Strength in 2 hours, MPa } & $\begin{array}{c}\text { Normal } \\
\text { density }\end{array}$ \\
\hline Start & End & Under compression & In bending & \\
\hline 7.40 & 9.30 & 7.0 & 3.35 & 0.68 \\
\hline
\end{tabular}

The degree of hydrophobicity of the material was increased by the addition of Aquasil [13]. Aquasil is an organic compound containing silicon. The degree of hydrophobicity of the surface of the samples was determined from the value of the contact angle of wetting, in accordance with the procedure of [14].

The water was used for tap water [15].

As a filler, we used cardboard with particle sizes less than $5 \mathrm{~mm}$. The grinding was carried out at the SM-100 cutting mill. Separation of dispersed cardboard into fractions was carried out by screening through standard sieves with a cell size of $5 ; 2.5 ; 1.25 ; 0.63 ; 0.315 ; 0.2 ; 0.1$ $\mathrm{mm}$.

Samples with a ratio of components of cardboard / gypsum - 0.5: $1 ; 1: 1 ; 1.5: 1 ; 2: 1$.

The determination of the strength parameters of the samples was carried out by the method, the essence of which is to determine the minimum loads destroying the sample. The compressive strength and bending strength was determined on the samples by beads measuring $4 \times 4 \times 16 \mathrm{~cm}$, according to the procedure given in GOST 23789 [15].

The mobility of gypsum dough before pouring into molds was determined using a Suttard device. To obtain high-filled cellulose-containing materials, studies have been carried out to determine the effect of the sequence of alignment of the initial components, the molding conditions and the properties of the final product. In this regard, three methods of combining components have been tested.

Method 1: Introduction of the crushed cellulosic filler into the finished gypsum dough.

Method 2. Moistening by reflux method of the crushed cellulose filler, dusting with gypsum binder with stirring, followed by molding the sample.

Crushed cardboard with a particle size limit of up to $5 \mathrm{~mm}$, was sieved, then moistened with water by irrigation. With mixing, there was a dusting with gypsum binder. The prepared mass was placed in a mold and subjected to compression. Method 3: The powdered cellulosic filler is powdered with a gypsum binder, moistened by irrigation with stirring, followed by molding the sample. The difference between method 3 and method 2 is the change in the sequence of alignment of the components of the mixture before molding.

\section{Results}

Investigations were carried out on the influence of the change in the ratio of cardboard / gypsum binder, the specific pressing pressure - Psp, the sequence of combination of components (methods 2,3 ) on the properties of the obtained samples.

The strength of the material was determined from the values of the flexural strength $\mathrm{Rf}$, upon compression until the sample RC was completely destroyed and at $10 \%$ strain RC10.

Figure 1 shows the change in the strength of the sample from the ratio of the components of cardboard/gypsum (pressing pressure $\mathrm{P}=0.5 \mathrm{MPa}$, the method of making the molding mass 2). 


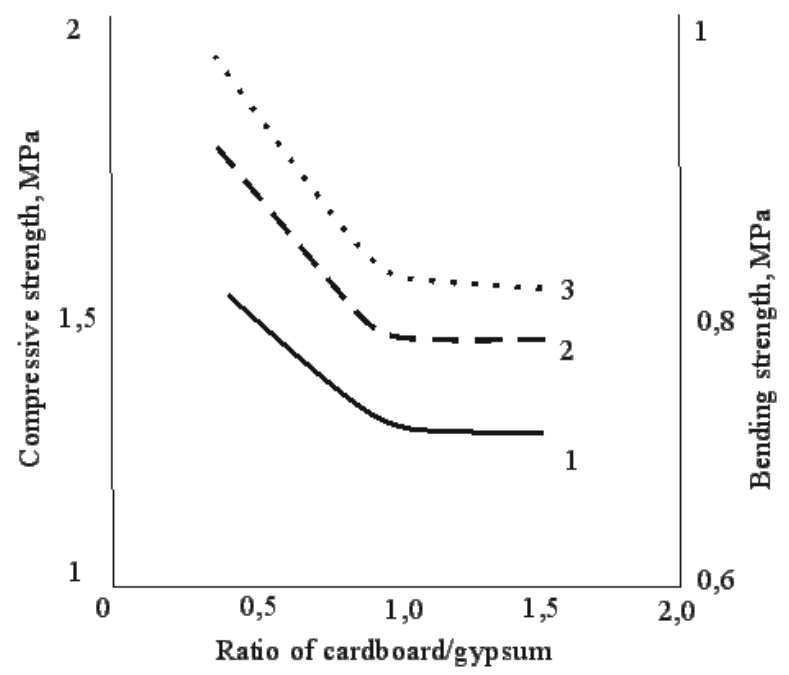

Fig. 1. The change in the strength characteristics: 1 - Rf; 2 - Rc10; 3 - Rc.

Figure 2 shows the change in the strength of the third technological method. Figure 3 shows the change in the strength characteristics of gypsum-fiber articles from the density (pressing pressure $\mathrm{P}=0.5 \mathrm{MPa}$, the method for making the molding mass 2). Figure 4 shows similar changes in strength characteristics, but the way of making the molding mass 3 . Figures 5, 6 show the results of testing the change in the average density of gypsum-fiber articles from the ratio of cardboard / gypsum and pressing pressure.

Due to the specific properties of the starting components, the resulting material has a high hydrophilicity. This narrows the scope of its application.

To impart hydrophobic properties, ensuring high water resistance, the molded samples were treated with an Aquasil water repellent with subsequent exposure at a temperature of $20^{\circ} \mathrm{C}$ for 24 hours. The degree of hydrophobicity of the surface of the samples was determined from the value of the contact angle of wetting. The value of the contact angle was within $125-132^{\circ}$.

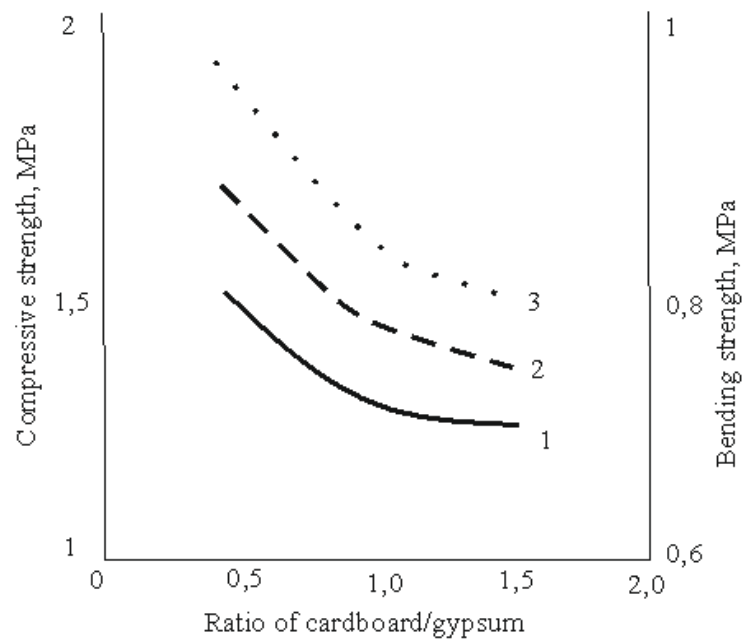

Fig. 2. The change in the strength characteristics of gypsum-fiber articles from the ratio of components (pressing pressure $\mathrm{P}=0.5 \mathrm{MPa}$, method of making the molding mass 3 ): $1-\mathrm{R}_{\mathrm{f}}, 2-\mathrm{Rc}^{10}$; $3-\mathrm{Rc}$. 


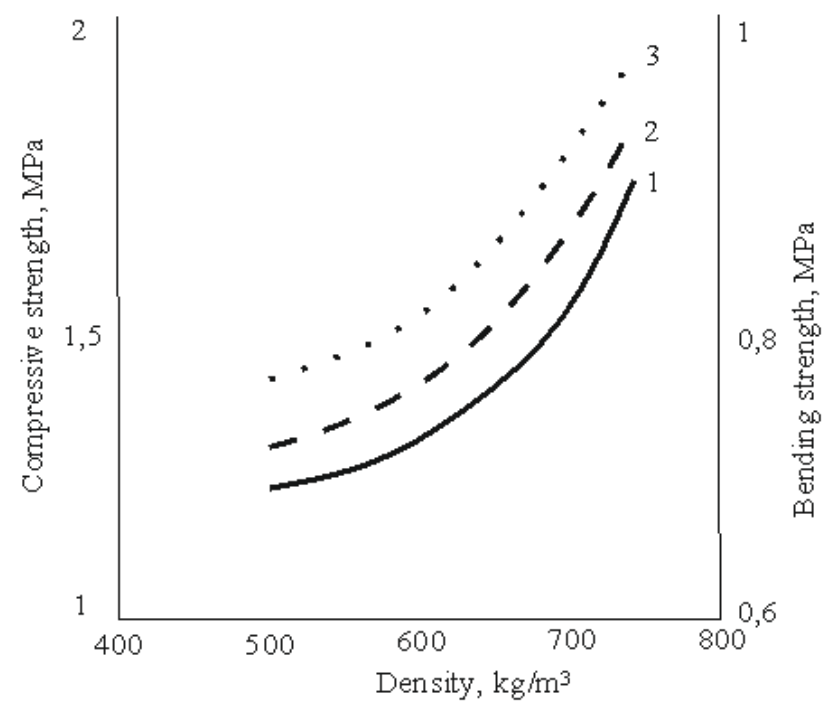

Fig. 3. The change in the strength characteristics: $1-\mathrm{R}_{\mathrm{f}} ; 2-\mathrm{Rc}^{10} ; 3-\mathrm{Rc}$.

\section{Conclusions}

As the studies have shown, the sequence of operations for obtaining molding masses significantly affects the technological terms of product formation, as well as the optimal values of the cardboard-gypsum ratio, the water-gypsum ratio $(\mathrm{V} / \mathrm{G})$ and the value of the maximum specific molding pressure of the gypsum board mass obtained.

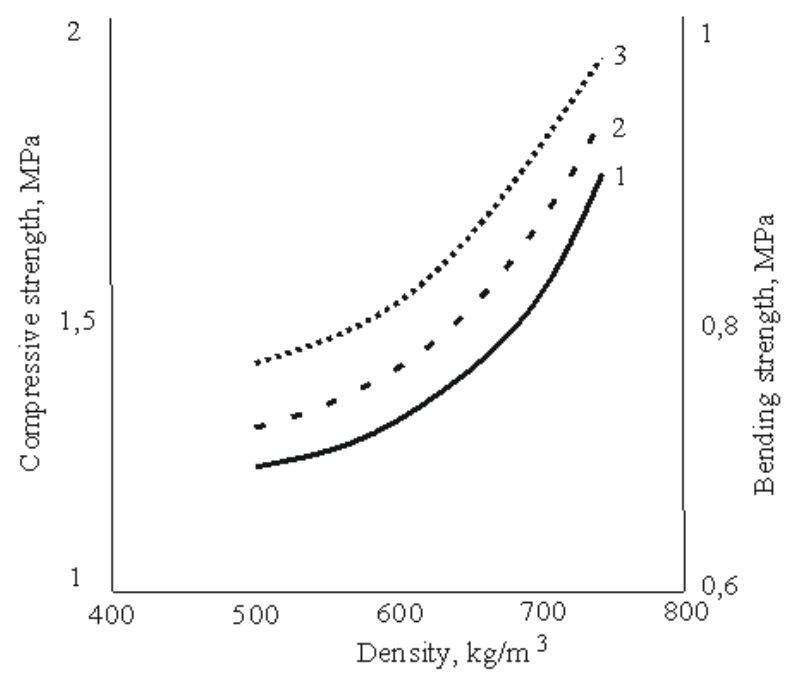

Fig. 4. The change in the strength characteristics of gypsum-fiber articles from the density (pressing pressure $\mathrm{P}=0.5 \mathrm{MPa}$, the method of making the molding mass 3 ): $1-\mathrm{R}_{\mathrm{f}} ; 2-\mathrm{Rc}^{10} ; 3-\mathrm{Rc}$. 


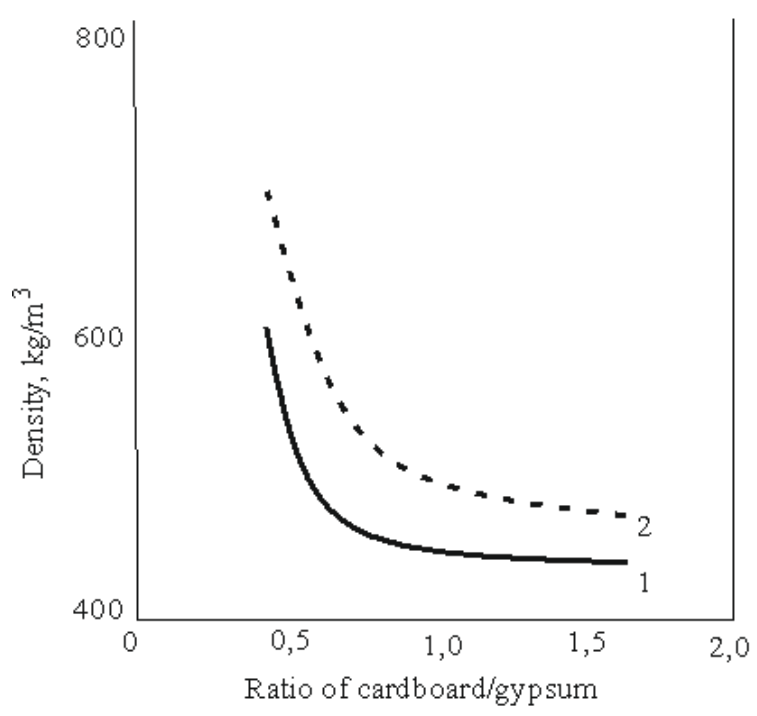

Fig. 5. The change in the average density of gypsum-fiber articles from the ratio of components and the pressing pressure (method of manufacturing the molding mass 2 ): $1-\mathrm{P}=0.05 \mathrm{MPa} ; 2-\mathrm{P}=0.5$ $\mathrm{MPa}$.

Depending on the given technological parameters, as well as the specified properties of the final product, the most optimal of the two methods for obtaining the molding mass is chosen. In order to obtain a material with a wider range of average density variations (from 420 to $750 \mathrm{~kg} / \mathrm{m}^{3}$ ), it is preferable to use a second method for producing the molding mass, as compared to method 3 . In this case, the strength value obtained by method 2 at the same average densities Higher than method 3.

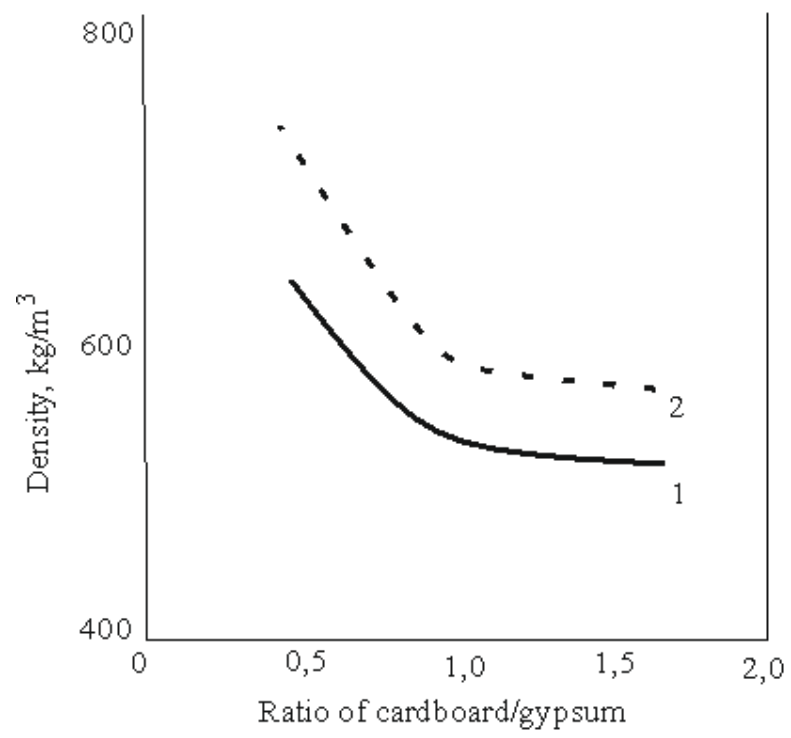

Fig. 6. Change in the average density of gypsum-fiber articles from the ratio of components and pressing pressure (the method of making the molding mass 3 ): $1-\mathrm{P}=0.05 \mathrm{MPa} ; 2-\mathrm{P}=0.5 \mathrm{MPa}$. 
This is due primarily to the fact that when the cardboard is pre-coated with a plaster cement with subsequent moistening, the water, first of all, combined with the gypsum binder causes its hydration.

In contrast to method 2, in method 3, water, falling onto the surface of a non-tart plasterboard-bound cardboard, actively migrates from the surface of the cardboard to the inside of its particle.

Upon subsequent dusting with a gypsum binder, the water in a sufficient amount for hydration is suitable for the latter, only when a certain molding pressure is generated. A significant amount of water remains inside the particle, which during the subsequent removal of moisture from the material, breaks the integrity of the mineral matrix, which leads to a decrease in the strength of the finished product. However, this method allows for a longer holding time of the molding composition just prior to molding, and also enables a longer process for molding the product.

The results obtained make it possible to use cellulose-containing solid household waste as fillers to produce highly filled cellulose-containing composites using gypsum binders. Depending on the quantitative ratio of the components, the molding conditions, the methods for producing the molding masses, it is possible to obtain a material with an average density of 400 to $800 \mathrm{~kg} / \mathrm{m}^{3}$ and compressive strength limits of 1 to $2 \mathrm{MPa}$, bending strengths from 1.1 to $1.4 \mathrm{MPa}$.

The water resistance can be achieved by treating the material with effective organosilicon compounds.

\section{References}

1. M. Novikov, Solid domestic waste 1(127), 30-32 (2017)

2. On the approval of the Federal Classification of Waste. Order of Rosprirodnadzor of 22.05.2017 N242 (Registered in the Ministry of Justice of Russia on 08.06.2017 N 47008)

3. http://www.priroda.su/item/5082

4. S. Kirsanov, G. Mustafin, Bul. of Omsk University. S. "Economics" 2, 114-120 (2014)

5. J. Aleluia, P. Ferrão, Waste Management 58, 415-429 (2016)

6. M. Jensen, J. Møller, C. Scheutz, Waste Management 49, 491-504 (2016)

7. U. Askarova, R. Mustafayeva, Actual problems of humanitarian and natural sciences 82, 12-14 (2014)

8. D. Grazhdani, Waste Management 48, 3-13 (2016)

9. S. Kubba, Green Building Materials and Products Chapter 6 LEED v4 Practices, Certification, and Accreditation Handbook (Second Edition) (2016)

10. http://government.ru/docs/19831/

11. M. Bruyako, L. Grigorieva, S. Frolova, Energy Safety and Energy Economy 3, 10-12 (2011)

12. V. Korovyakov, A. Ferronskaya, L. Chumakov, Gypsum materials and products (production and use). Directory (Izd. ASV, Moscow, 2004)

13. TU 2229-003-60543126-2014

14. M. Kiselev, V. Savich, T. Pavich, Science and Technology 1, 38-41 (2006)

15. Russian Standard GOST 23789 -79 